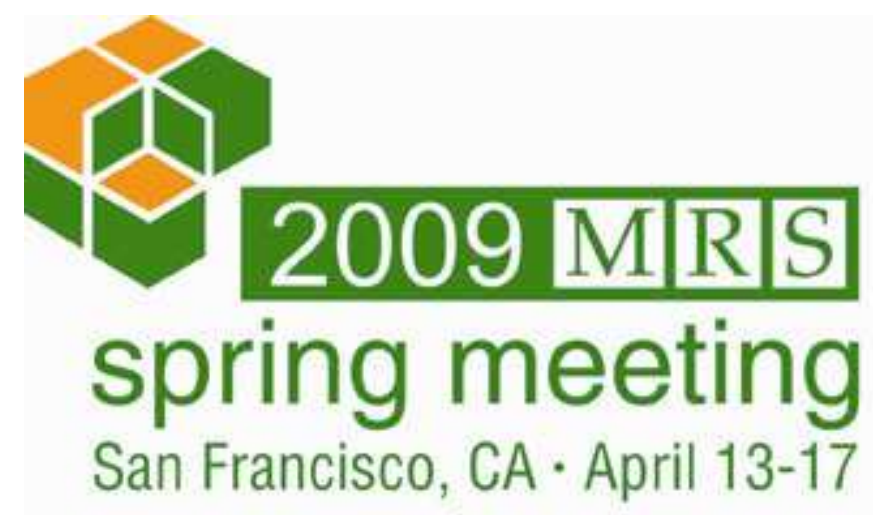

\title{
ZnO Microcrystals for Light Emitting Diode and Photovoltaic Applications with Integration on Flexible Substrates
}

\begin{tabular}{|r|l|}
\hline Journal: & 2009 MRS Spring Meeting \\
\hline Manuscript ID: & 1192-PP13-05.R1 \\
\hline Symposium: & Symposium PP \\
\hline Date Submitted by the \\
Author: & 20 -Oct-2009 \\
\hline $\begin{array}{r}\text { Complete List of Authors: } \\
\text { Keywords: }\end{array}$ & $\begin{array}{l}\text { Cole, Jesse; University of Minnesota, Electrical Engineering } \\
\text { Jacobs, Heiko; University of Minnesota, Electrical Engineering }\end{array}$ \\
\hline & \\
\hline
\end{tabular}

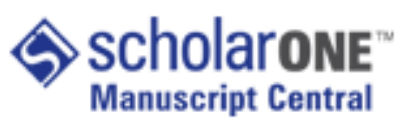




\title{
ZnO Microcrystals for Light Emitting Diode and Photovoltaic Applications with Integration on Flexible Substrates
}

Authors: Jesse J. Cole and Heiko O. Jacobs

Affiliation: Dept. of Electrical Engineering, University of Minnesota, Minneapolis, MN 55455

\begin{abstract}
We report a new integration approach to produce arrays of $\mathrm{ZnO}$ microcrystals for optoelectronic and photovoltaic applications. Demonstrated applications are $n-\mathrm{ZnO} / \mathrm{p}-\mathrm{GaN}$ heterojunction LEDs and photovoltaic cells. The integration process uses an oxygen plasma treatment in combination with a photoresist pattern on Magnesium doped GaN substrates to define a narrow sub-100nm width nucleation region. $\mathrm{ZnO}$ is synthesized in the defined areas by a hydrothermal technique using zinc acetate and hexamethylenetetramine precursors. Nucleation is followed by lateral epitaxial overgrowth producing single crystal disks of $\mathrm{ZnO}$. The process provides control over the dimension and location of the $\mathrm{ZnO}$ crystals. The quality of the patterned $\mathrm{ZnO}$ is high; the commonly observed defect related emission in the electroluminescence spectra is suppressed and a single near-band-edge UV peak is observed. Transfer printing of the $\mathrm{ZnO}$ microcrystals onto a flexible substrate is also demonstrated in the context of transparent flexible electronics.

INTRODUCTION
\end{abstract}

$\mathrm{ZnO}$ micro and nanostructures have been produced using a large number of different synthetic routes ${ }^{[1]}$ and the applications that utilize the unique properties keep increasing. The $3.3 \mathrm{eV}$ direct bandgap and $60 \mathrm{meV}$ exciton binding energy is exploited in ultraviolet optoelectronics $^{[2-4]}$, room temperature lasing ${ }^{[5-8]}$, and solar cells applications ${ }^{[9-11]}$; extremely long photocarrier lifetimes have been observed yielding UV photodetectors with 108 internal gain ${ }^{[12]}$; the optical properties in combination with n-type conduction support transparent transistor and display applications ${ }^{[13,14]}$ while the piezoelectricity is utilized in power generation ${ }^{[15]}$ and force sensing applications ${ }^{[4]}$. The integration of these device prototypes on a wafer scale will require access to $\mathrm{ZnO}$ micro and nanostructures with a variety of dimensions at known locations. A wet chemical approach is desired for reasons of processing cost when compared with gas-phase methods and a number of patterned and seeded growth methods have been reported. Patterned self-assembled monolayers with hydrophobic and hydrophilic endgroups have been used on silver ${ }^{[16]}$ or silicon substrates ${ }^{[17]}$ yielding densely packed $400 \mathrm{~nm}$ diameter and $2 \mu \mathrm{m}$ long $\mathrm{ZnO}$ nanorods in regions that were $2 \mu \mathrm{m}$ wide with empty areas in between. Out-of-plane orientation varied but has been improved by seeding $\mathrm{ZnO}$ nanocrystals through thermal oxidation of zinc acetate $^{[18]}$. Perfect vertical orientation, however, requires substrates such as $\mathrm{GaN}, \mathrm{MgAl}_{2} \mathrm{O}_{4}{ }^{[19]}$, or Sapphire ${ }^{[20]}$ which can be partially masked with photoresist to achieve patterned growth. Qualitatively all of these methods produce nanorods in the seeded or unmasked areas with limited control over the location and density. Continued growth leads to coalescence into a polycrystalline film as the diameter increases with grain boundaries and defects in between. Continued growth in combination with photoresist has also been reported to lead to a lateral overgrowth; a previously reported concept to produce high quality $\mathrm{GaN}$ thin films ${ }^{[21]}$. For $\mathrm{ZnO}$ on $\mathrm{MgAl}_{2} \mathrm{O}_{4}$, lateral growth over patterned photoresist improved the dislocation density by a factor of 100 compared to the window region containing coalesced nanorods ${ }^{[19]}$. Subsequent growth using a second window yielded continuous $\mathrm{ZnO}$ thin films with reduced dislocations ${ }^{[20]}$.

This paper reports on a new method using oxygen plasma to surface engineer nucleation areas to produce vertical single crystal $\mathrm{ZnO}$ nanowire rows, extended walls, and disk type 
structures on p-type GaN at addressable locations on a surface with tailored $>100 \mathrm{~nm}$ lateral dimensions and sub-100nm lateral positional accuracy. The concept uses a plasma process and photoresist patterns to reveal non-oxidized magnesium sites that nucleate growth. Nucleation in non-oxidized areas is followed by epitaxial overgrowth producing patterned areas of $\mathrm{ZnO}$ over 2 inch wafers. Adjusting $\mathrm{pH}$ increased $\mathrm{ZnO}$ deposition yield and enabled formation of high quality $\mathrm{ZnO}$ crystals. $\mathrm{ZnO} / \mathrm{GaN}$ micro-LEDs and solar cells were fabricated. The LEDs possessed strong near band edge electroluminescent emission. Deep-level defect emission in the red and yellow is absent which implies that the $\mathrm{ZnO}$ microcrystals are of high quality. A hexagonal star radiation pattern is observed which is explained by light emission through crystallographic facets.

\section{RESULTS AND DISCUSSION}

(A)

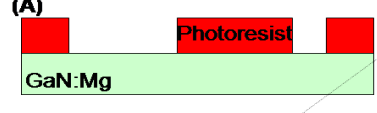

(B) Oxygen Plasma

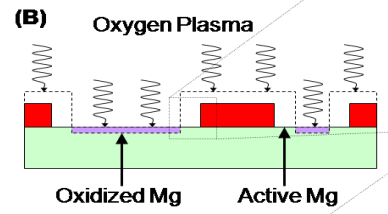

(c)

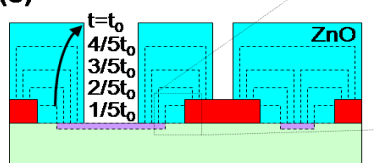

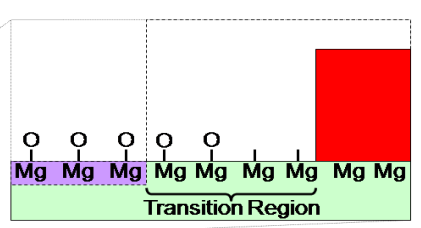

Zno

o o o o oznoznd

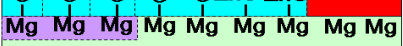

Figure 1. Process steps for producing $\mathrm{ZnO}$ crystals through nucleation at the photoresist-GaN interface. (A) Conventionally patterned photoresist on $\mathrm{Mg}$ doped $\mathrm{GaN}$ is exposed to an (B) oxygen plasma to deactivate $\mathrm{Mg}$ dopands that otherwise act as nucleation sites as well as to produce (B close-up) a transitional region which contains non-oxidized $\mathrm{Mg}$ to nucleate growth. (C) Solution growth at different $\mathrm{pH}$ and growth time yields individual (left), and merged laterally overgrown $\mathrm{ZnO}$ structures (right). The merged structures can fill the photoresist opening which eases LED device fabrication (Fig. 5).

Figure 1 shows the patterned growth process. Photolithography, oxygen plasma treatment, and solution-based growth are the basic process steps to produce $\mathrm{ZnO}$ micro and nanocrystals at exact locations on a surface. The oxygen plasma is used to oxidize $\mathrm{Mg}$ dopands to inhibit nucleation and growth in the center area while it etches the resist leaving behind a transitional region to nucleate $\mathrm{ZnO}$ growth. Subsequent lateral epitaxial overgrowth yields $\mathrm{ZnO}$ structures that are larger in diameter than the initial nucleation region. The patterned surface (Fig. 1A) is formed with standard photolithography on a Mg-doped GaN substrate, doping concentration $5 \times 1018 \mathrm{~cm}-3$, TDI inc., Silver Spring, MD. Following a prebake at $115^{\circ} \mathrm{C}$ for $60 \mathrm{~seconds}$, Shipley 1805 photoresist was spun at 3000 RPM, soft-baked at $105^{\circ} \mathrm{C}$ for 60 seconds, exposed using a Karl Suss MA-6 Mask Aligner, and developed in Microposit 351 developer for 30 seconds. The patterns can directly be used for growth leading to a polycrystalline $\mathrm{ZnO}$ film in the exposed GaN areas which shows that the basic developer containing sodium hydroxide and exposure to photoresist do not adversely affect $\mathrm{ZnO}$ nucleation on p-type GaN. However, to produce single crystal structures of high quality a plasma treatment is required (Fig. 1B). The treatment yields a narrow nucleation region where the oxidation state transitions from fully oxygen passivated to partially and non-oxidized while it removes organic residues on the GaN surface which is required to accomplish uniform growth over the entire wafer. We optimized this process and exposure to a 100-watt, 100 mTorr oxygen plasma for 30 seconds worked best to completely prevent nucleation on fully oxygen passivated $\mathrm{Mg}$-doped $\mathrm{GaN}$. The growth of $\mathrm{ZnO}$ (Fig. 1C) is carried out in a glass vial and based on a previously published procedure ${ }^{[16]}$. In short, growth is initiated by adding zinc acetate, $\mathrm{Zn}\left(\mathrm{CH}_{3} \mathrm{COO}\right)_{2}$, and hexamine, $\left(\mathrm{CH}_{2}\right)_{6} \mathrm{~N}_{4}$, to $70 \mathrm{~mL}$ of deionized water such that the solution contained $25 \mathrm{mM}$ of each compound. To grow the $\mathrm{ZnO}$ crystals, the solution was heated in an oven to $90^{\circ} \mathrm{C}$ for times ranging between 10 minutes to 3 hours. Following the growth, samples were removed from solution and briefly rinsed with DI water. While this is the basic process we found that the initial $\mathrm{pH}$ of the growth solution is an important additional parameter to control. The glass vial initially contained deionized water at 
$\mathrm{pH}$ 5.5; the slightly acidic nature is attributed to $\mathrm{CO}_{2}$ absorption from the ambient environment. It was necessary to increase the initial $\mathrm{pH}$ to 7.5 by adding small amounts of ammonium hydroxide, $\mathrm{NH}_{4} \mathrm{OH}$, to form continuous extended single crystals.

Figure 2 shows images of $\mathrm{ZnO}$ structures that form at the plasma activated interface; with an increase in $\mathrm{pH}$ from 5.5 to 7.5 the crystals transition from individual $\mathrm{ZnO}$ nanorods (Fig. 2A,B) to single crystal lines with a rectangular $1 \mu \mathrm{m}$ wide and $0.8 \mu \mathrm{m}$ tall crossection (Fig. $2 \mathrm{C}, \mathrm{D})$. Independent of the $\mathrm{pH}$ no nucleation and growth is observed on either the photoresist or the GaN. The presence of $\mathrm{Mg}$ dopants is the key element to accomplish the observed localized nucleation in some areas and passivation in others. A number of control experiments have been carried out which support this claim. First, we were not able to produce single crystals with high dimensional control on undoped and n-doped $\left(5 \times 10^{17} \mathrm{~cm}^{-3} \mathrm{Si}\right) \mathrm{GaN}$ samples in concurrent growth experiments $\left(90\right.$ minutes, $90^{\circ} \mathrm{C}, 25 \mathrm{mM}$ zinc acetate, $25 \mathrm{mM}$ hexamethylenetetramine, initial $\mathrm{pH} 7.5)$ with p-doped $\left(5 \times 10^{18} \mathrm{~cm}^{-3} \mathrm{Mg}\right) \mathrm{GaN}$ control substrates. The undoped and n-type samples produced $\mathrm{ZnO}$ structures with uncontrolled nucleation sites. The effect of the Magnesium can be explained by looking at the electronnegativity. Magnesium is an alkaline earth metal that exhibits greater ionic characteristics and lower electronegativity than the group III element gallium. Mg-O (oxygen electronegativity: 3.5) is more energetically stable than Mg$\mathrm{N}$ (nitrogen electronegativity: 3.1). The enhanced ionic characteristic of magnesium within the GaN lattice should lead to an enhanced concentration and attachment of precursor ions such as $\mathrm{OH}^{-}, \mathrm{Zn}^{2+}$, and their complexes. The affinity of $\mathrm{OH}^{-}$and subsequent localized decomposition of $\mathrm{Zn}(\mathrm{OH})_{2}$ is expected to lead to a preferential nucleation and growth in the Mg-rich region. Second, plasma oxidized $\mathrm{Mg}$ sites should block $\mathrm{OH}^{-}$attachment and suppress growth in areas towards the center of exposed GaN. This is consistent with the experiment. We observed complete deactivation of the nucleation sites through oxygen plasma treatment and this was only possible on $\mathrm{Mg}$ doped substrates. Third, the treatment with photoresist is not the primary cause of the suppressed growth in the center region. $\mathrm{ZnO}$ will grow in this area; elimination of growth requires the plasma treatment. Finally, the deactivation of the nucleation sites can be directly confirmed by plasma treatment of a bare p-type GaN chip that was partially covered with a glass slide. Subsequent growth revealed a $1.5 \mu \mathrm{m}$-thick continuous polycrystalline $\mathrm{ZnO}$ film in the non-oxidized areas, and no $\mathrm{ZnO}$ in the area that was fully exposed to the plasma. In summary, $\mathrm{Mg}$ sites are active and readily oxidized. The formation of an ionic $\mathrm{Mg}-\mathrm{O}$ bond upon exposure to the energetic oxygen ions leads to the deactivation of the nucleation sites.

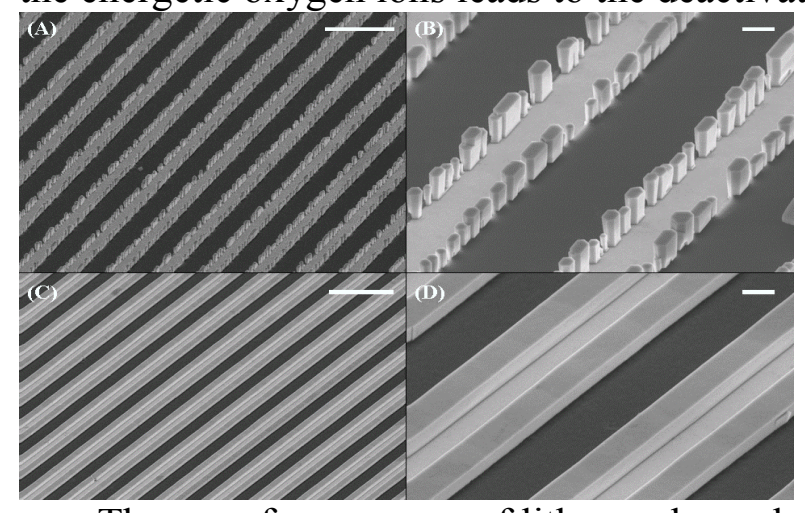

Figure 2. Patterned integration of $\mathrm{ZnO}$ structures through nucleation at the $\mathrm{GaN}$ (bright)photoresist(dark) interface. (A, B) Nanorods with an average diameter of $300 \mathrm{~nm}$ and $(\mathrm{C}, \mathrm{D})$ continuous waveguide-like structures with uniform rectangular cross-section are shown. Selectivity is large and no $\mathrm{ZnO}$ nucleation or growth is observed on either photoresist or oxygen passivated $\mathrm{p}-\mathrm{GaN}$. Increasing the initial growth condition from $\mathrm{pH} 5.5$ to 7.5 caused the transition from isolated $(\mathrm{A}, \mathrm{B})$ to continuous $\mathrm{ZnO}$ single crystal structures (C,D). $10 \mu \mathrm{m}$ scale bar in (A,C). $1 \mu \mathrm{m}$ scale bar in (B,D).

The use of a sequence of lithography and oxidation steps did not adversely affect previously passivated nucleation sites. This allows for the formation of more complex nucleation areas. Figure 3 shows a set of $\mathrm{ZnO}$ wall and interdigitated electrode type structures formed using a two step sequence. The first sequence used photolithography, plasma oxidation, and removal of resist 
to produce parallel lines of fully oxidized GaN. Next the process was repeated whereby the photoresist pattern crosses the original pattern at controlled angles; the wall structures (Figs. 3A,B) had an angle of $90^{\circ}$, and the interdigitated electrode structures (Figs. 3C,D) had an angle of roughly $1^{\circ}$ between the initial oxidized GaN strips and final photoresist trenches; the resist is not removed during the second step to yield narrow nucleation regions and illustrated structures.

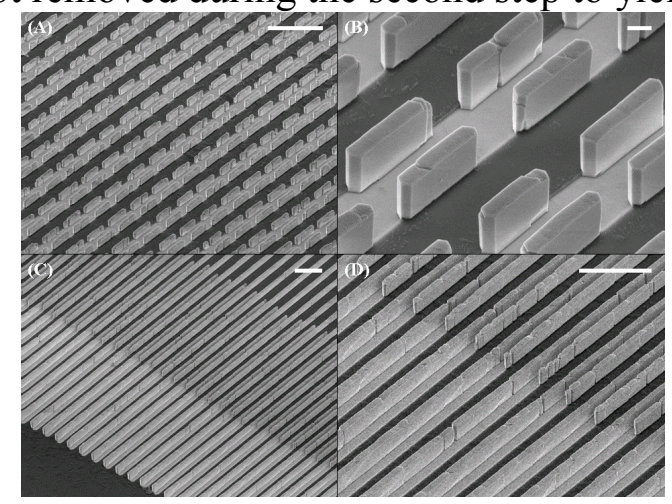

Figure 3. $\mathrm{ZnO}$ structures fabricated by multiple oxidation steps. Angle between initially oxidized $\mathrm{GaN}$ strips and final $\mathrm{ZnO}$ nucleation strips was varied from $90^{\circ}(\mathrm{A}, \mathrm{B})$ to approximately $1^{\circ}(\mathrm{C}, \mathrm{D})$, resulting in walls and interdigitated electrode type structures, respectively. $10 \mu \mathrm{m}$ scale bar in (A,C,D). $1 \mu \mathrm{m}$ scale bar in (B).

Process parameters including growth time and layout of the nucleation sites can further be modified to form larger crystal domains with well controlled dimensions. Figure 4 shows an example, photoresist with $3 \mu \mathrm{m}$ diameter circular openings and $6 \mu \mathrm{m}$ center-to-center spacing were oxygen plasma treated, resulting in ring-shaped $\mathrm{ZnO}$ nucleation areas along the circumference of each hole. $\mathrm{ZnO}$ deposited initially in the ring-shaped regions (inset Fig. 4A), then merged by lateral overgrowth over a longer growth time of 3 hours to become the wellfaceted hexagonal crystals. The largest interior dimensions of the hexagonal crystals were $4 \mu \mathrm{m}$, indicating that $\mathrm{ZnO}$ laterally overgrew the photoresist hole by $\sim 0.5 \mu \mathrm{m}$. Lateral overgrowth occurred over the oxidized $\mathrm{GaN}$ as well, such that $\mathrm{ZnO}$ filled the photoresist holes to completely cover the GaN surface. Using the photomasks the structures can be placed with a positional accuracy (40 nm, STD) calculated by measuring the center-to-center distance of the $\mathrm{ZnO}$ crystal that have been produced, specifically Figs. 2B, 3D, 4A. The use of higher resolution e-beam patterns could reduce these numbers. Lateral overgrowth leads to merged crystals with a narrow size distribution (15\%, STD) calculated by analyzing top down dimensions (Fig. 2D, Fig. 4A).

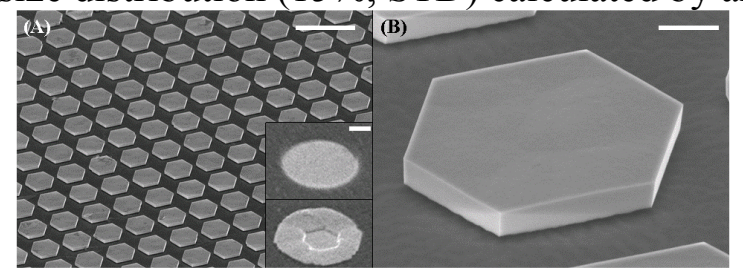

Figure 4. Images depicting a square array of $\mathrm{ZnO}$ hexagons with well controlled dimensions and spacing. The structures are nucleated from (A insets) $3 \mu \mathrm{m}$-diameter rings and (B) merge together into single crystals. $10 \mu \mathrm{m}$ scale bar in (A). $1 \mu \mathrm{m}$ scale bar in (A insets, B).

Figure 5 shows an array of ultraviolet heterojunction $n-\mathrm{ZnO} / \mathrm{p}-\mathrm{GaN}$ LEDs produced using the growth process to study the electrooptical properties. There have been a number of reports on $\mathrm{n}-\mathrm{ZnO} / \mathrm{p}-\mathrm{GaN}$ heterojunction LEDs. Recent work has replaced the polycrystalline $\mathrm{ZnO}$ thin films ${ }^{[2,22-24]}$ with $\mathrm{ZnO}$ nanowires ${ }^{[3,25,26]}$ to take advantage of the nanowire properties - high crystallinity and fewer grain boundaries. The results are interesting: one report showed electroluminescence (EL) under reverse bias while the other reported forward bias emission ${ }^{[25,26]}$. A follow up study in our own group confirmed low efficiency reverse bias emission ${ }^{[4]}$ which was attributed to tunneling breakdown where hot carrier injection and recombination predominantly occurred in the GaN film. Most of the previous devices including our own ${ }^{[4]}$ suffered from defect related emission around $585 \mathrm{~nm}$. The improved device structure shown in Fig. 5A completely eliminates the defect related emission. The fabrication is detailed in the supplemental section. In short, the device was formed using the hexagonal $\mathrm{ZnO}$ disks (Fig. 4A) that completely filled the 
openings in the insulating photoresist matrix. This overgrowth method provides an advantage over earlier designs that required deposition of an insulating layer and polishing or etching to expose the top of the $\mathrm{ZnO}$. Applied forward bias revealed a six-pointed star of violet light under a 10x optical microscope objective (Fig. 5B) which cannot be explained by the layout of the array which has a square lattice. Higher resolution analysis using a 50x objective (Fig. 5B inset) showed areas of high light intensity to match directions perpendicular to the hexagonal $\mathrm{ZnO}$ facets which suggests that some light is transmitted and coupled preferentially along directions perpendicular to $\mathrm{ZnO}$ facets. We have not yet changed the dimension and spacing between the $\mathrm{ZnO}$ microLEDs to study coupling or lasing. Electroluminescence data (Fig. 5C) shows nearband-edge violet and ultraviolet emission from the $\mathrm{ZnO}-\mathrm{GaN}$ heterojunction, and absence of any peaks in the 500 to $750 \mathrm{~nm}$ wavelength range, where deep-level $\mathrm{ZnO}$ crystal defects commonly radiate light. $^{[4,27]}$ The absence of deep-level radiative defects indicates that $\mathrm{ZnO}$ deposited using plasma-defined nucleation areas is a high quality material.

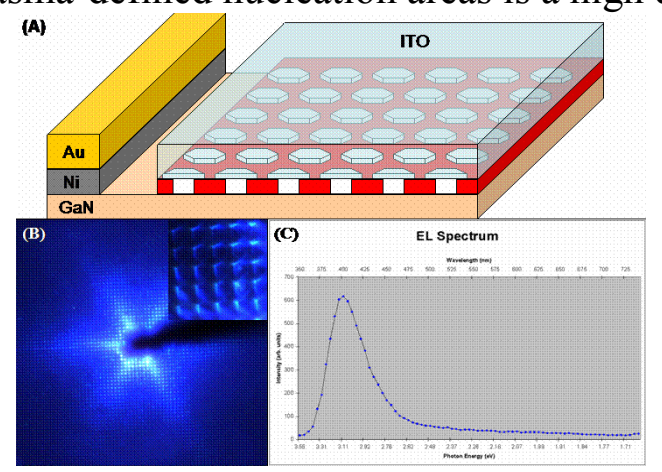

Figure 5. Heterojunction $\mathrm{n}-\mathrm{ZnO} / \mathrm{p}-\mathrm{GaN}$ ultraviolet LED. (A) Device structure. (B) Forward bias emission revealing a six-pointed star which is attributed to facet-to-facet (inset) hexagonal propagation. (C) Electroluminescence spectrum showing near-band-edge emission at $3.11 \mathrm{eV}$ and absence of defect peaks in the wavelength range 500 to $750 \mathrm{~nm}$.

Illumination with a 6 watt handheld ultraviolet lamp caused the $\mathrm{ZnO}-\mathrm{GaN}$ hexagonal heterojunctions (again Fig. 5A) to function as a photovoltaic cell. The maximum open circuit voltage and short circuit junction current density was found to be $450 \mathrm{mV}$ and $70 \mathrm{~mA} / \mathrm{cm}^{2}$, respectively. First order estimates yielded 1-9\% electrical quantum efficiency. We do not have a precise number since the size of the active junction is presently not known with sufficient accuracy. The ITO formed a successful contact to about 100-300 $\mathrm{ZnO} / \mathrm{GaN}$ junctions which was determined from the forward bias emission picture. As individual junction area we used $10 \mu \mathrm{m}^{2}$ which represented the photoresist opening which assumes that the oxygen passivated and overgrown area does not limit transport. The junction efficiency would be larger if this assumption is incorrect.

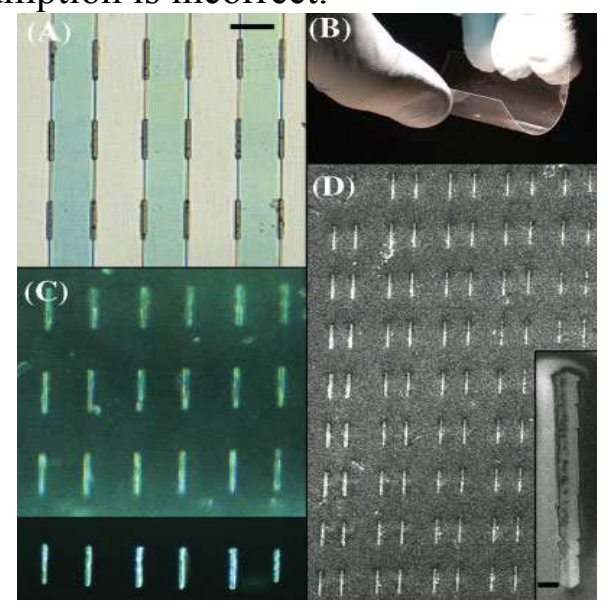

Figure 6. $\mathrm{ZnO}$ transfer to a flexible substrate. Fabricated $\mathrm{ZnO}$ prior (A) and after transfer (B-D) onto a $200 \mathrm{~mm}$ thick epoxy-PET flexible substrate. Dark field (C), fluorescence (C, inset), and SEM (D) micrographs of $\mathrm{ZnO}$ epoxy composite structure after transfer. $25 \mathrm{~mm}$ scale bar in (A). $2 \mathrm{~mm}$ scale bar in (D inset).

Figure 6 shows a first example transferring a 10x10 array of $25 \mu \mathrm{m}$ long and $2 \mu \mathrm{m}$ wide crystals onto an epoxy thin film. We supported the $\mathrm{ZnO}$ structures prior transfer by spin-coating 
a $10 \mu \mathrm{m}$ thin layer of SU-8 2010 onto the structure $\left(2500 \mathrm{RPM}, 95^{\circ} \mathrm{C} / 120 \mathrm{~s}\right.$ soft-bake, $20 \mathrm{~s} \mathrm{UV}$ exposure, and $95^{\circ} \mathrm{C} / 120 \mathrm{~s}$ hard bake). The use of a low viscosity SU-8 solution helped to form a conformal initial coating. Subsequently we applied a second $200 \mu \mathrm{m}$ thick layer (100 RPM, $95^{\circ} \mathrm{C} / 300$ s soft-bake, $120 \mathrm{~s}$ UV exposure, and $95^{\circ} \mathrm{C} / 1 \mathrm{~h}$ hard bake) to produce a film with sufficient mechanical strength. The entire epoxy film (Fig. 6A) including the $\mathrm{ZnO}$ can be delaminated through rapid thermal cooling induced stress by placing the sample on an unheated copper plate at the end of the final hard bake cycle. The film tends to curl and was further attached to a polyethylene terephthalate (PET) film to characterize the flexible and optically transparent $\mathrm{ZnO}$ and SU-8 composite structure (Fig. 6B-D). The SEM micrographs of the ZnO crystals suggest that the crystals remain intact after transfer. The micrographs of transferred $\mathrm{ZnO}$ show the bottom side which was previously in contact with portions of the GaN substrate (about $60 \%$ ) and photoresist (about 40\%) surface. The structures mirror the topography and show a reduced thickness on the partially overgrown photoresist. We attribute the ability to transfer intact $\mathrm{ZnO}$ crystals to their relatively thin thickness of $3 \mu \mathrm{m}$ and the reduced adhesive force in the laterally overgrown areas on the resist. We have not yet measured the electrical mobility of these crystals as a function of bending radius and applied stress and strain.

\section{CONCLUSION}

The reported nucleation and growth process provides a new route towards the production of $\mathrm{ZnO}$ micro and nanostructures at known locations (40nm-STD) with well defined dimensions (15\%-STD). The process produces high quality $\mathrm{ZnO}$ where deep-level radiative defects are eliminated. In addition to the demonstrated micro LEDs/photovoltaic cells these two features are attractive for a number of applications that aim at integrating devices such as ultraviolet LEDs ${ }^{[2-}$ ${ }^{4]}$, laser cavities ${ }^{[28]}$, waveguides ${ }^{[5-8]}$, high gain photodetectors ${ }^{[12]}$, solar cells ${ }^{[9-11]}$, sensors, piezoelectric actuators ${ }^{[4]}$ or micro-power generators ${ }^{[15]}$ at exact known locations.

\section{ACKNOWLEDGMENTS}

We acknowledge support of this work by NSF CMMI-0621137.

\section{REFERENCES}

[1] Z. Fan, J. G. Lu, Journal of Nanoscience and Nanotechnology 2005, 5, 1561.

[2] R. D. Vispute, V. Talyansky, S. Choopun, R. P. Sharma, T. Venkatesan, M. He, X. Tang, J. B. Halpern, M. G. Spencer, Y. X. Li, L. G. Salamanca-Riba, A. A. Iliadis, K. A. Jones, Applied Physics Letters 1998, 73, 348.

[3] X. Wang, J. Cole, A. M. Dabiran, H. O. Jacobs, "ZnO Nanowire/p-GaN Heterojunction LEDs", presented at Mater. Res. Soc. Symp. Proc., Warrendale, PA, 2007.

[4] X. Wang, J. Cole, H. O. Jacobs, "Electroluminescence of ZnO Nanowire/p-GaN Heterojunction Light Emitting Diodes", presented at Proc. 2007 NSTI Nanotechnology Conference, Santa Clara, CA, 2007.

[5] P. Yang, H. Yan, S. Mao, R. Russo, J. Johnson, R. Saykally, N. Morris, J. Pham, R. He, H.-J. Choi, Advanced Functional Materials 2002, 12 , 323.

[6] H. Yan, J. Johnson, M. Law, R. He, K. Knutsen, J. R. McKinney, J. Pham, R. Saykally, P. Yang, Advanced Materials (Weinheim, Germany) 2003, 15, 1907.

[7] R. Hauschild, H. Kalt, Applied Physics Letters 2006, 89, 123107/1.

[8] L. K. van Vugt, S. Ruehle, D. Vanmaekelbergh, Nano Letters 2006, 6, 2707.

[9] M. Law, E. Greene Lori, C. Johnson Justin, R. Saykally, P. Yang, Nature Materials 2005, 4, 455

[10] S. Leschkies Kurtis, R. Divakar, J. Basu, E. Enache-Pommer, E. Boercker Janice, C. B. Carter, R. Kortshagen Uwe, J. Norris David, S.

Aydil Eray, Nano Letters 2007, 7, 1793.

[11] C. Levy-Clement, R. Tena-Zaera, M. A. Ryan, A. Katty, G. Hodes, Advanced Materials (Weinheim, Germany) 2005, 17, 1512

[12] C. Soci, A. Zhang, B. Xiang, S. A. Dayeh, D. P. R. Aplin, J. Park, X. Y. Bao, Y. H. Lo, D. Wang, Nano Letters 2007, 7, 1003.

[13] S. Ju, K. Lee, D. B. Janes, M.-H. Yoon, A. Facchetti, T. J. Marks, Nano Letters 2005, 5, 2281.

[14] M. Futua, H. Furuta, T. Matsuda, T. Hirao, T. Hiramatsu, H. Hokari, M. Yoshida, Materials Integration 2006, $19,10$.

[15] J. Schrier, D. O. Demchenko, L.-W. Wang, A. P. Alivisatos, Nano Letters 2007, 7, 2377.

[16] J. W. P. Hsu, Z. R. Tian, N. C. Simmons, C. M. Matzke, J. A. Voigt, J. Liu, Nano Letters 2005, 5, 83.

[17] Y. Masuda, N. Kinoshita, F. Sato, K. Koumoto, Crystal Growth \& Design 2006, 6, 75.

[18] L. E. Greene, M. Law, D. H. Tan, M. Montano, J. Goldberger, G. Somorjai, P. Yang, Nano Letters 2005, 5, 1231.

[19] D. Andeen, J. H. Kim, F. F. Lange, G. K. L. Goh, S. Tripathy, Advanced Functional Materials 2006, 16, 799.

[20] J. H. Kim, D. Andeen, F. F. Lange, Advanced Materials (Weinheim, Germany) 2006, 18, 2453.

[21] S. Nakamura, M. Senoh, S.-i. Nagahama, N. Iwasa, T. Yamada, T. Matsushita, H. Kiyoku, Y. Sugimoto, T. Kozaki, H. Umemoto, M. Sano,

K. Chocho, Applied Physics Letters 1998, 72, 211. 


\section{Page 7 of 7}

[22] Y. I. Alivov, E. V. Kalinina, A. E. Cherenkov, D. C. Look, B. M. Ataev, A. K. Omaev, M. V. Chukichev, D. M. Bagnall, Applied Physics Letters 2003, 83, 4719 .

[23] Y. I. Alivov, J. E. Van Nostrand, D. C. Look, M. V. Chukichev, B. M. Ataev, Applied Physics Letters 2003, 83, 2943.

[24] A. Osinsky, J. W. Dong, M. Z. Kauser, B. Hertog, A. M. Dabiran, P. P. Chow, S. J. Pearton, O. Lopatiuk, L. Chernyak, Applied Physics Letters 2004, 85, 4272.

[25] W. I. Park, G.-C. Yi, Advanced Materials (Weinheim, Germany) 2004, 16, 87.

[26] M.-C. Jeong, B.-Y. Oh, M.-H. Ham, J.-M. Myoung, Applied Physics Letters 2006, 88, 202105/1.

[27] J. Bao, M. A. Zimmler, F. Capasso, X. Wang, Z. F. Ren, Nano Letters 2006, 6, 1719.

[28] M. H. Huang, S. Mao, H. Feick, H. Yan, Y. Wu, H. Kind, E. Weber, R. Russo, P. Yang, Science (Washington, DC, United States) 2001, 292, 1897. 